\title{
A reconstrução da experiência democrática: a democracia como credo pedagógico na filosofia de Dewey
}

\section{Reconstruction of the democratic experience: democracy as a pedagogical belief in Dewey's philosophy}

\author{
Altair Alberto Fávero** \\ Carina Tonieto ${ }^{* * *}$
}

\begin{abstract}
Resumo: $O$ texto tem por objetivo reconstruir e analisar as razões que levaram o educador americano John Dewey a eleger a democracia como credo pedagógico de sua filosofia da educação. Para tanto, inicialmente se fará uma breve reconstrução das origens da democracia na paideia grega para em seguida analisarem-se os motivos que levaram Dewey a eleger a democracia como principal referência do seu credo pedagógico. Nos dois últimos tópicos analisa-se a concepção democrática de educação na obra Democracia e Educação e por que Dewey utiliza a ciência, a filosofia e a educação como instrumentos na reconstrução da democracia.
\end{abstract}

Palavras-chave: Experiência democrática. Pragmatismo. Políticas educacionais. Filosofia.

\begin{abstract}
The present article aims at reconstructing and analyzing the reasons that led the American educator John Dewey to elect democracy as the pedagogical belief of his educational philosophy. In order to do so, firstly our work will briefly retrace the origins of democracy at the Greek paideia, in order to analyze the reasons that led Dewey to choose democracy as the main reference of his pedagogical belief. Finally, we will discuss the democratic concept of education on Dewey's work Democracy and Education and the reasons why the author uses science, philosophy, and education as instruments of reconstruction of the democracy.
\end{abstract}

Keywords: Democratic experience. Pragmatism. Educational policies. Philosophy.

\footnotetext{
* Texto vinculado ao projeto de pesquisa "Pragmatismo, filosofia e educação: as interfaces entre experiência, reflexão e políticas de ensino", institucionalizado junto à Vice-Reitoria de Pesquisa e Pós-Graduação. O projeto é coordenado pelo autor do presente texto e foi produzido a partir das discussões realizadas no grupo de pesquisa vinculado ao projeto. Participam do grupo os seguintes membros: Marceli Andresa Becker, Carina Tonieto, Francieli Nunes da Rosa, Claudeonor de Vargas, Gabriela de Sousa, Henrique Miotto e Jorge Alexandre Bieluczyk.

** Professor do Programa de Pós-Graduação em Educação da Universidade de Passo Fundo. E-mail: <favero@upf.br>

*** Mestre em Educação pelo Programa de Pós-Graduação em Educação da Universidade de Passo Fundo/ RS. Professora de Filosofia e Sociologia na rede privada e pública de ensino. E-mail: <katonieto@gmail.com>
} 
Devemos salientar, porém, que faz̧er da democracia uma condição de êxito, não é tarefa muito fácil. A moderna teoria educativa diz-nos que não aprendemos senão aquilo que praticamos. Se quisermos aprender democracia, devemos praticá-la (KILPATRIC, 1978, p. 55).

\section{Considerações iniciais}

Nos últimos trinta anos ocorreram tantas transformações nos aspectos sociais, políticos, culturais e econômicos, que, possivelmente, não há comparativos com outras épocas da história. Transformações sempre existiram, e sua efetivação possibilita a evolução da sociedade. No entanto, as dos últimos tempos apresentam algumas características especiais: são rápidas, profundas, complexas e paradoxais. No campo educacional não poderia ser diferente. Vivemos hoje um momento em que o cenário educativo se transforma de forma muito rápida e nem sempre conseguimos acompanhar o real o significado que essas mudanças representam.

Há quase oitenta anos, era traduzida e editada no Brasil a famosa obra "Educação para uma civilização em mudança" do educador americano William Kilpatrick (1978), o qual já indicava o papel que a educação teria de assumir diante das demandas criadas por uma civilização em mudança. Se, nas sociedades marcadas por pouca mobilidade, a ação educativa poderia se restringir à transmissão de ideias, atitudes e sentimentos das instituições já consolidadas, em sociedades marcadas pelas intensas mudanças necessita-se de ações educativas que consigam ser sensíveis às profundas transformações em curso. Por isso, para Kilpatrick, era necessário fomentar "o pensamento baseado na experimentação" como forma de possibilitar um processo educacional compatível com as exigências de uma civilização em mudança, marcada por três tendências fundamentais: a) uma nova atitude mental diante da vida; b) a industrialização; c) a democracia (KILPATRIC, 1978, p. 20). O que essas tendências possuem em comum com os desafios educacionais? Por que a democracia é indicada como uma das exigências de uma civilização em mudança? Por que os educadores/pensadores que esculpiram os pressupostos das teorias educativas modernas colocaram a democracia como um dos grandes ideais a serem conquistados?

O texto que segue tem por objetivo reconstruir e analisar as razões que levaram John Dewey a eleger a democracia como credo pedagógico de sua filosofia da educação. Para tanto, inicialmente, faremos uma breve reconstrução das origens da democracia na paideia grega para, em seguida, analisar os motivos que o levaram a eleger a democracia como sua principal referência. Nos dois últimos tópicos analisaremos a concepção democrática de educação na obra "Democracia e educação" e a razão por que Dewey utiliza a ciência, a filosofia e a educação como instrumentos na reconstrução da democracia. 


\section{As origens do conceito de democracia na paideia grega}

A ideia de democracia vem de longa data. A magistral civilização grega nos legou os termos demos (povo) e kratos (poder) = poder do povo, que ainda hoje continuam presentes no imaginário popular. A palavra "democracia", sem os eufemismos ou distorções que facilmente pode sofrer, significa o exercício do poder transparente, público, visível, pelo qual o povo pode expressar sua vontade, fiscalizar seus escolhidos, decidir como quer ser governado. A polis Atenas do século V a.C., considerada o grande exemplo da democracia do mundo antigo, deixou-nos o legado da possibilidade de pensar uma forma institucional de organizar a sociedade, na qual o poder não se concentra nas mãos de uma única pessoa (monarquia) nem nas mãos de poucos (aristocracia), mas, sim, deve ser exercido por muitos.

Ao examinar o universo espiritual da polis, Jean-Pierre Vernant (1996) destaca que o seu aparecimento constitui, na história do pensamento grego, um acontecimento decisivo, uma imprescindível invenção, não só no plano intelectual, mas, igualmente, no domínio das instituições. Para Vernant (1996, p. 34-42), a constituição/invenção da polis trouxe três características fundamentais: (I) a palavra torna-se o instrumento político por excelência, a chave de toda a autoridade do Estado, o meio de comando e de domínio sobre outrem; (II) publicidade e transparência às manifestações mais importantes da vida social; (III) isonomia ou igual participação de todos os cidadãos no exercício do poder. O que há de especial/extraordinário em cada uma dessas três características? Por que seriam decisivas nos contornos que a ideia de democracia tomaria na sociedade ocidental? Vejamos cada uma delas.

Ao se tornar proeminente sobre todos os outros instrumentos de poder, a palavra deixa de ser apenas um termo ritual ou uma fórmula justa e passa a ser o espaço público do debate contraditório, da discussão, da argumentação. Assim, passa a existir uma relação estreita, um vínculo recíproco entre a política e o logos. As decisões não são mais tomadas "às escondidas", na forma de preceitos "sagrados", mas passam a necessitar da força do argumento, da arte oratória, do debate antitético. Justamente por isso, a retórica, a sofística e a lógica ganham terreno fértil na cultura grega.

Quanto à característica de publicidade e transparência às manifestações mais importantes da vida social, ela permite mais amplamente "o acesso ao mundo espiritual, reservado no início a uma aristocracia de caráter guerreiro e sacerdotal" (VERNANT, 1996, p. 35). Assim, os conhecimentos, os valores e as técnicas mentais são levados à praça pública, sujeitos às mais diversas interpretações, aos mais controvertidos debates, às mais inusitadas oposições. É por isso que a escrita terá um papel importante para os gregos, pois "poderá 
satisfazer a essa publicidade porque ela própria tornou, quase com o mesmo direito da língua falada, o bem comum de todos os cidadãos" (VERNANT, 1996, p. 36). A escrita se tornará a base da paideia grega, assim como garantirá a permanência e fixidez das leis. A lei escrita, diz-nos Vernant (1996, p. 37), torna-se "regra comum a todos", "sujeita à discussão" e "modificável por decreto". A "sacralidade" também perde o seu caráter privado e se torna pública, observando-se que a própria legislação da polis transforma os cultos privados em cultos oficiais da cidade. "A proteção que a divindade reservava outrora a seus favoritos", ressalta Vernant (1996, p. 38), "vai doravante exercer-se em benefício da comunidade toda". Iguais publicidade e transparência dos bens culturais não tiveram outras civilizações do mesmo período histórico. A civilização egípcia, por exemplo, apesar de ter sido uma grande e poderosa civilização, não teve a "grandeza" de tornar públicos os conhecimentos, os valores e as técnicas que produziu; limitada a uma casta sacerdotal subserviente ao poder absoluto do faraó, sucumbiu esquecida com a derrocada da própria civilização.

Quanto à "isonomia ou igual participação de todos os cidadãos no exercício do poder", Vernant destaca que, "apesar de tudo o que os opõe no concreto da vida social, os cidadãos se concebem, no plano político, como unidades permutáveis no interior de um sistema cuja lei é o equilíbrio, cuja norma é a igualdade" (VERNANT, 1996, p. 42). Assim, continua Vernant, as relações entre os diversos indivíduos que compõem a polis, as múltiplas atividades desenvolvidas no cotidiano tomam "a forma de uma relação recíproca, reversível, substituindo as relações hierárquicas de submissão e de domínio" (VERNANT, 1996, p. 42).

Não resta dúvida de que havia imperfeições na democracia grega. $\mathrm{O}$ fato de as mulheres, os menores de idade e os escravos serem excluídos da participação dos debates e decisões da polis coloca em suspenso a suposta "perfeição" da democracia ateniense. Embora não nos interesse, neste texto, fazer uma análise exaustiva dessas contingências históricas, não podemos nos esquecer de que estamos nos referindo ao século $\mathrm{V}$ a.C. e que há todo um contexto a ser considerado. $\mathrm{O}$ que nos interessa aqui é perceber que há um potente elo entre o modo democrático como os gregos organizaram sua vida social e a maneira como objetivaram sua formação educacional (paideia).

Em seu famoso livro Paideia, ao definir o lugar dos gregos na história da educação, Werner Jaeger (1989, p. 4) afirma que "a Grécia representa, em face dos grandes povos do Oriente, um 'progresso' fundamental, um novo 'estádio' em tudo o que se refere à vida dos homens em comunidade". Tal afirmação é corroborada por Jaeger ao contrastar o modo de vida dos gregos com

a exaltação oriental dos homens-deuses, solitários, acima de toda a medida natural, onde se expressa uma concepção metafísica que nos é totalmente estranha; em contraste com a opressão das massas, sem a qual não seria concebível a exaltação dos soberanos e a sua significação religiosa. (JAEGER, 1989, p. 7). 
É por isso que o modo de vida dos gregos poderia ser interpretado na linha da liberdade do indivíduo dos tempos modernos, pois toda a cultura grega conspira na direção de formar um ideal de homem: a forma humana dos seus deuses, o predomínio evidente do problema da forma humana na sua escultura e pintura, o movimento da filosofia do problema do cosmo para o problema do homem, o estilo de poesia e, finalmente, no Estado grego. "Este ideal de Homem, segundo o qual se devia formar o indivíduo", esclarece Jaeger (1989, p. 11), "não é um esquema vazio, independente do espaço e do tempo. É uma forma viva que se desenvolve no solo de um povo e persiste através das mudanças históricas". Por isso a superior força do espírito grego depende do seu "profundo enraizamento na vida comunitária" e só pode ser compreendida nessa dinâmica de experiência comunitária. É o que leva Jaeger a afirmar que "a educação grega não é uma soma de técnicas e organizações privadas, orientadas para a formação de uma individualidade perfeita e independente", só possível de ser efetivada numa "atmosfera de íntima liberdade" (JAEGER, 1989, p. 12).

Vinte e cinco séculos nos distanciam dessa fabulosa invenção da democracia e sua estreita relação com a educação. O que há de atual no legado grego? Em que sentido a experiência democrática dos gregos pode se tornar atual para se pensar a organização social de nosso tempo? Em que medida a paideia grega pode servir de referência para se enfrentarem os atuais desafios educacionais? Não faltam evidências para confirmar o manancial inesgotável dos gregos para pensar os problemas educacionais de nosso tempo. Como herdeiros longínquos deste legado, temos o compromisso e o desafio de atualizar a experiência democrática que eles tão bem souberam atrelar à configuração de sua paideia. Nos próximos tópicos deste texto, nossa intenção é analisar de que maneira os ideais gregos são atualizados na filosofia e experiência democrática do americano John Dewey.

\section{A democracia como credo pedagógico em John Dewey}

Filosofia e educação foram, certamente, as duas inseparáveis áreas de interesse de Dewey durante toda a sua vida. Por isso, não seria exagero chamá-lo de "filósofo da educação".

Depois de concluir a curso de Artes na Universidade de Vermont em 1979, orientou-se para os estudos de filosofia doutorando-se na área em 1884, na Universidade de Hopkins, com uma tese a respeito da psicologia de Kant (CUNHA, 1994, p. 17). A partir de então, passou a ser professor em três universidades americanas: Michigan (1884-1894), Chicago (1894-1904) e Columbia (1904-1930). Sua atuação nessas três importantes instituições foi decisiva para consagrar seu credo pedagógico na democracia. Na primeira (Michigan) 
encontrou um ambiente democrático, "que incentivava as responsabilidades e a liberdade dos jovens diante do sistema de ensino" (CUNHA, 1994, p. 17). Na Universidade de Chicago fundou a Escola Laboratório, onde pôde experimentar suas ideias de educação progressista. $\mathrm{Na}$ interpretação de alguns dos estudiosos do filósofo da educação, suas atividades nesta universidade "foi justamente o decênio em que se plasmaram fundamentalmente suas idéias sobre educação, assim como muito de sua filosofia" (AMARAL, 1990, p. 32). Ainda sobre esse período, cabe ressaltar sua convivência com a organização de assistência social Hull House, dirigida por Jane Adams.

A Hull House procurava romper com o espírito filantrópico que permeava as iniciativas de ajuda aos pobres; seu princípio elementar era baseado no estabelecimento de relações recíprocas de auxílio, uma vez que as disparidades sociais eram vistas por Jane Adams como geradoras de dependência mútua entre as classes sociais. Se, de um lado, havia famílias necessitadas de ajuda material e espiritual, de outro, havia jovens instruídos, de classe média e superior, que precisavam dar vazão a seus sentimentos de fraternidade; Adams propunha-se a colocar esses jovens em ação, de modo a aplacar sua consciência dos desequilibrios sociais (MILLS, 1960 apud CUNHA, 1994, p. 21).

O filósofo da educação via neste tipo de convivência e neste modo diferenciado de praticar o espírito filantrópico uma forma de convivência humana compatível com os princípios democráticos por ele idealizados.

Dewey adotou a democracia como o único e verdadeiro fundamento para a sua filosofia e como o credo inabalável para postular suas ideias educacionais. Quais os motivos que o levaram a tal opção? Que situações vivenciais foram preponderantes para que o filósofo da educação tivesse semelhante convicção para afirmar tal credo? Em grande parte, a resposta a essas questões se explica em razão do próprio ambiente em que Dewey foi criado e que favoreceu a sua formação democrática. Se retomarmos a trajetória intelectual e social do filósofo americano, podemos perceber que sua formação democrática é resultado de três grandes influências: (I) a atuação das comunidades congregacionais; (II) a vida social dos pioneiros americanos; (III) as raízes filosóficas de sua formação.

Em relação à primeira, a gênese da colonização americana foi marcada pelo desejo de constituir um projeto de sociedade independente e autônoma, diferente do modelo que caracterizava o regime monárquico inglês. É por isso que nos Estados Unidos nunca um rei subiu ao trono para governar o país. Os ancestrais de Dewey imigraram para a Nova Inglaterra por volta de 1630, fugindo das perseguições religiosas e, ao se estabelecerem na nova pátria, adotaram o protestantismo congregacionista como forma de organização social e religiosa. "Os congregacionistas só aceitavam a autoridade de sua própria congregação, rejeitando qualquer autoridade externa" (AMARAL, 1990, p. 34). Logo, cada 
comunidade era livre para formular suas próprias normas de fé, contrapondo-se a dogmas externos que viessem a estabelecer hierarquias entre os membros da comunidade. No entendimento de Maria Nazaré Amaral, “isso revelava o caráter democrático das mesmas, pois as almas como que se aproximavam umas das outras livremente, sem qualquer sentimento de desigualdade” (AMARAL, 1990, p. 35).

$\mathrm{O}$ fato dos ministros e magistrados serem escolhidos entre os próprios membros das comunidades congregacionais revela uma forma democrática de organização, que se contrapunha, por exemplo, à teocracia clerical própria do catolicismo. Assim, podemos dizer que a atuação das comunidades congregacionistas influenciava o credo pedagógico de Dewey na democracia. Nesse sentido, tem razão Jane Dewey, uma das mais importantes biógrafas do filósofo da educação, quando faz a seguinte observação:

O ambiente de sua meninice, embora não marcado por uma autêntica democracia industrial e financeira, criou nele uma fé inconsciente, mas vital na democracia, que emergiu à consciência, constituindo o fundamento da maior parte de seus escritos filosóficos. (DEWEY, 1971 apud AMARAL, 1990, p. 34).

No que toca à segunda - a vida social dos pioneiros americanos -, em vários de seus escritos, Dewey explicita uma íntima ligação entre vida humana associada e vida democrática. O que leva Dewey a fazer essa ligação? Que traços contextuais o levaram a estabelecer essa ligação? Por que coloca a fé na democracia como "forma de associação humana por excelência"? De que modo a vida social dos pioneiros americanos inspiraria o credo pedagógico deweyano?

Para compreender melhor o cenário e analisar com maior propriedade a influência que a vida social dos pioneiros americanos teve na constituição da democracia como credo pedagógico em Dewey, pensamos que seja oportuno nos apropriarmos de algumas passagens da clássica obra de Aléxis Tocqueville (1985) "A democracia na América". O escrito de Tocqueville é considerado o primeiro manifesto sobre o mito americano da democracia. O livro é resultado das viagens que o autor francês realizou nos Estados Unidos, onde observou e recolheu informações acerca da civilização e política norte-americanas. Além de estudar a história e a tradição política dos americanos e suas influências na constituição das instituições ( $1^{\mathrm{a}}$ parte do livro), Tocqueville analisa as influências das instituições sobre os costumes ( $2^{a}$ parte). A obra é reveladora do intenso interesse dos pensadores políticos do velho continente pela "nova democracia", que deixa de ser um mero reflexo do pensamento europeu para constituir-se em objeto de reflexão sobre a política do futuro. Em "A democracia na América" há uma preocupação básica, que consiste no seguinte paradoxo: "como evitar que o igualitarismo (que considerava uma característica da civilização americana) ameaçasse a liberdade individual, ou, em outras palavras, como impedir que se instaurasse a tirania da maioria” (LAMOUNIER, 1985, p. 181). 
O entusiasmo de Tocqueville pela América é visível em várias passagens. Como exemplo, transcrevemos algumas:

É nas leis da Nova Inglaterra que se vê nascer e desenvolver-se essa dependência comunal que forma, ainda atualmente, como que o princípio e a vida da liberdade americana [...]. No seis da comuna, vê-se reinar uma política real e ativa, inteiramente democrática e republicana. [...] reinava completa igualdade entre os emigrantes que vieram estabelecer-se nas costas da Nova Inglaterra. O próprio germe da aristocracia nunca foi depositado nesta parte da União. Ali só se pôde alcançar fundamentos de influências intelectuais. O povo habituou-se a reverenciar certos nomes como emblemas de luzes e virtudes (TOCQUEVILLE, 1985, p. 194-196).

O espírito democrático e a recusa de constituir uma aristocracia ou um governo despótico aparecem de forma transparente nos escritos de Tocqueville. Não é de estranhar, portanto, que a vida social democrática dos pioneiros americanos tenha impressionado e influenciado na indicação da democracia como credo pedagógico de Dewey.

Há uma terceira influência - talvez a mais importante - que marcou decisivamente a formação democrática de Dewey: trata-se das raízes filosóficas de sua formação. Consideramos esta terceira influência a mais importante porque é nela que ele irá buscar apoio racional para sustentar seu credo pedagógico na democracia. Possivelmente, uma primeira influência intelectual que o direcionou à ideia de democracia como união de todos na vida comunitária tenha acontecido na Universidade de Vermont, sob a orientação de T. H. Huxley (não seria interessante colocar o nome completo por extenso?). Ao frequentar o curso de fisiologia ministrado por Huxley, Dewey ficou profundamente impressionado pelas teses darwinistas que lhe forneceram uma noção bastante atraente da interconexão dos seres no mundo. $\mathrm{O}$ depoimento desta influência é dado pelo próprio Dewey no texto "From absolutism to experimentalism", quando diz:

Subconscientemente, pelo menos, fui levado a desejar um mundo e uma vida com as mesmas propriedades do organismo humano numa imagem derivada do estudo do darwinismo conforme o tratamento de Huxley. De qualquer modo, obtive mais estímulo desse estudo do que de qualquer outro contato tido antes e, como nenhum desejo foi despertado em mim para continuar nesse ramo particular de conhecimento, eu dato desse tempo o despertar de um interesse filosófico distinto (DEWEY, 1930 apud AMARAL, 1990, p. 40).

Dewey via na teoria da evolução de Darwin uma forma analógica de conceber a vida em sociedade: assim como no mundo os seres formam uma unidade na qual cada um cumpre, por meio da organização própria, uma função em benefício do todo, na comunidade humana há um princípio de igualdade entre os seres que se torna a característica fulcral da vida democrática. 
Ainda em Vermont há outra influência intelectual que conflui para os interesses teóricos desse autor: trata-se dos estudos sobre o "Curso de filosofia" de Augusto Comte. A influência de Comte não se traduz na incorporação deweyana da lei dos três estados, mas na "ideia da necessidade de encontrar uma função social para a ciência, como meio de evitar a desorganização da vida existente" (AMARAL, 1990, p. 41). A estudiosa de Dewey, Maria Nazaré de C. Pacheco Amaral, flagra na obra "A busca da certeza" algumas passagens em que o filósofo da educação revela ter sido influenciado por Comte: "homem que vive em um mundo onde reina o azar, vê-se obrigado a buscar a segurança” (COMTE, 1970 apud AMARAL, 1990, p. 42). Na tentativa de buscar segurança, o homem, inicialmente, ancora-se na súplica, no rito, no culto mágico ou na religião. Quando essas formas não garantem mais a segurança, o homem a busca, então, no estado científico ou positivo. Vemos nessas passagens, portanto, uma certa influência positivista.

Outra influência intelectual foi o seu contato com o pensamento de Hegel, agora na Universidade de Johns Hopkins. Sob a orientação do professor de filosofia George Sylvester Morris, Dewey encontrou em Hegel o alimento intelectual de que precisava para consolidar sua fé na unidade do mundo. É de Dewey o seguinte depoimento: "A síntese hegeliana do sujeito e do objeto, da matéria e do espírito, do divino e do humano não era, contudo, mera forma intelectual; ela operava em mim como um alívio imenso, uma liberação" (DEWEY, 1930 apud AMARAL, 1990, p. 43). Esse "alívio imenso", essa "libertação", explicitada por Dewey, consistiam um poderoso apoio racional para justificar intelectualmente e de modo prático suas aspirações fervorosas de unidade.

Mais uma influência, não menos importante, foi a leitura dos "Princípios de psicologia", de William James, os quais, na avaliação da biógrafa Jane Dewey, "foram em grande parte a maior influência singular para mudar a direção do pensamento filosófico de Dewey” (DEWEY, 1930 apud AMARAL, 1990, p. 44). Dewey toma de James a ideia de que há duas tendências irreconciliáveis na psicologia: uma origina-se na visão tradicional da psicologia como teoria da consciência; a outra fundamenta-se na biologia, da qual deriva uma concepção biológica da mente. É por esta segunda tendência que Dewey teria sido mais fortemente influenciado. O depoimento é do próprio Dewey (1930):

Duvido que tenhamos até o momento começado a realizar tudo o que devemos a William James pela introdução e uso dessa idéia. [...] De qualquer modo, ela penetrou mais e mais em todas as minhas idéias e atuou como um fermento na transformação das velhas crenças. (DEWEY, 1930 apud AMARAL, 1990, p. 45).

Esse fermento de transformação foi o que possibilitou a Dewey adotar o modelo biológico de adaptação do homem ao meio como forma de explicar o desenvolvimento das ações humanas. 
A tarefa de compreender a democracia como credo pedagógico em Dewey não pode ser dada como concluída sem que antes se explicite a sua concepção democrática de educação. É o que veremos no próximo tópico.

\section{A concepção democrática de educação em Dewey}

A obra "Democracia e educação", publicada pela primeira vez em 1916, em meio à Primeira Guerra Mundial, é considerada pelos seus estudiosos, a mais importante obra educacional do pensamento de Dewey. Embora não seja um autêntico e genuíno tratado de pedagogia, aborda questões de psicologia, problemas filosóficos, temas das ciências sociais, além de investigar as múltiplas questões educacionais. O próprio filósofo da educação expressa no prefácio desta fundamental obra educacional a intenção que o motivara a escrevê-la:

Este livro é um esforço para penetrar e definir as idéias implícitas em uma sociedade democrática e para aplicá-las aos problemas da educação. A exposição inclui a indicação dos fins e métodos construtivos da educação pública, encarados desse ponto de vista, e ainda uma crítica das teorias do conhecimento e da moral, formuladas em condições sociais primitivas e que continuam a atuar nas sociedades nominalmente democráticas, obstando a realização adequada do ideal democrático (DEWEY, 1959a, p. 2).

Já nas primeiras páginas do capítulo dedicado a apresentar a concepção democrática da educação, Dewey procura explicitar as diferenças que se produzem no espírito, no material e no método da educação, quando se utilizam diferentes tipos de organização social. "Dizer que a educação é uma função social que assegura a direção e o desenvolvimento dos imaturos, por meio de sua participação na vida da comunidade que pertencem", ressalta Dewey, "equivale, com efeito, a afirmar que a educação variará de acordo com a qualidade da vida que predominar no grupo" (DEWEY, 1959a, p. 87).

Compreender a educação como função social na perspectiva deweyana equivale a dizer que uma sociedade que almeja "mudança" e faz da "transformação" um ideal de vida necessita ter normas e métodos educativos diferentes de sociedades que não aspiram a semelhantes ideais. Por isso, Dewey critica o conceito abstrato de sociedade, que, em razão da sua ambiguidade, não possibilita um claro discernimento de sua intencionalidade. Dizer que uma sociedade ou comunidade, por sua própria natureza, é portadora de qualidades intrínsecas, tais como "comunhão de bons propósitos e bem-estar", ou "fidelidade aos interesses públicos e reciprocidade de simpatia", pode esconder diversas mazelas de más associações. O próprio filósofo da educação exemplifica tais circunstâncias ao dizer que "há entre ladrões sentimentos de honra e uma quadrilha de salteadores tem um interesse comum a vincular todos os seus componentes" 
(DEWEY, 1959a, p. 88). Assim, não é sensato acreditar que o termo "sociedade" ou "comunidade" carrega "em-si” um propósito nobre. Portanto, há a necessidade de critérios de julgamento, de uma medida de valor, para analisarmos os diversos modos de vida social. Porém, ao definir tais critérios, Dewey nos alerta no sentido de se evitarem dois extremos: de um lado, não podemos criar uma sociedade ideal, pois facilmente cairemos numa divagação alienante; por outro, não podemos simplesmente reproduzir de forma passiva a sociedade existente. "O problema", ressalta Dewey, "consiste em extrair os traços desejáveis das formas de vida social existente e empregá-los para criticar os traços indesejáveis e sugerir melhorias" (DEWEY, 1959a, p. 89).

Dewey define o "interesse comum", "certa porção de interação" e a "reciprocidade coletiva com outros grupos" como critérios de julgamento para definir os traços desejáveis e indesejáveis das formas de vida, aplicando-os, primeiramente, a duas formas de associação. "Se aplicarmos estas considerações a uma quadrilha de malfeitores, por exemplo," diz Dewey, "verificaremos que os elos que conscientemente lhe vinculam os membros são pouco numerosos e quase que reduzidos ao só interesse comum do roubo, e que são de natureza a isolar o grupo dos outros grupos, no tocante ao mútuo dar e receber dos valores da vida" (DEWEY, 1959a, p. 89). Por isso, este tipo de educação é parcial e falseada. Algo diferente acontece se tomarmos a vida familiar. Neste grupo não são os interesses restritos que imperam, nem a interação momentânea que se esgota quando são atingidos limitados propósitos, mas "há muitos interesses conscientemente comunicados e compartilhados - existem vários e livres pontos de contato com outras modalidades de associações" (DEWEY, 1959a, p. 89).

Dewey amplia a aplicação dos critérios apresentados para as diferentes formas de governo. Ao analisar um país governado despoticamente, Dewey ressalta que há uma espécie de instrumentalização das ações dos súditos, reduzindo-as ao único propósito de evitar a dor e obter o prazer. É por isso que os déspotas apelam para o medo como forma de dominar seus súditos. Assim, em sociedades despoticamente governadas "não há grande número de interesses comuns; não há livre reciprocidade do dar e receber entre os membros de um grupo social; o estímulo e a reação mostram-se muito unilaterais" (DEWEY, 1959a, p. 90). Mas por que é tão importante ampliar o compartilhamento de interesses comuns, realizar de forma mais abrangente a reciprocidade entre os membros de uma sociedade e efetivar a multilateralidade dos estímulos e reações? A resposta deweyana é implacável: "a experiência de cada uma das partes perde em significação quando não existe o livre entrelaçamento das várias atividades da vida" (DEWEY, 1959a, p. 90). É por isso que na separação entre a classe privilegiada e a classe submetida, os membros da primeira são educados para serem senhores, e os membros da segunda, para serem escravos. Todos perdem com essa forma 
de separação e educação, pois as atividades das classes de condição menos favorecidas tendem a se converter em rotina, ao passo que as das classes abastadas tendem a se tornar caprichosas, impulsivas e sem objetivos. Os males que afetam a classe superior, por serem menos materiais, são menos perceptíveis, mas são igualmente reais e geram uma cultura estéril e inútil. Nas palavras do próprio Dewey:

Sua cultura tende a tornar-se estéril, a voltar-se para se alimentar de si mesma; sua arte torna-se uma ostentação espetaculosa e artificial; sua riqueza se transmuda em luxo; seus conhecimentos superespecializam-se; e seus modos e hábitos se tornam mais artificiais do que humanos (DEWEY, 1959a, p. 90-91).

As constatações de Dewey são importantes no sentido de demonstrar as consequências desastrosas, tanto para os indivíduos quanto para a sociedade e suas diversas formas de associação, do fato de o isolamento, o exclusivismo e interesse particular e imediato se colocarem acima da interação coletiva. "A verdade fundamental é que o isolamento tende a gerar, no interior do grupo, a rigidez e a institucionalização formal da vida, e os ideais estáticos e egoístas" (DEWEY, 1959a, p. 92). O isolamento e o segregacionismo já fizeram parte da história da humanidade. Em comunidades primitivas, os termos "estrangeiro" e "inimigo" eram considerados sinônimos, o que representava a identificação de sabedoria na observância rígida dos costumes antigos; por sua vez, em sociedades plurais, altamente evoluídas, tendem a ser mais um empecilho para o crescimento do que uma forma de preservar tradições e saberes historicamente elaborados. Por isso, para Dewey, somente na democracia seria possível a concretização eficaz dos critérios de interesse comum (reciprocidade) e a cooperação mais livre entre os grupos sociais.

O ideal democrático proposto por Dewey não se limita a compreender a democracia como uma simples forma de governo. Escolher pelo sufrágio popular o próprio governante não é fator suficiente para dizer que tal sociedade ou associação vive de forma democrática. "Uma democracia", ressalta de forma contundente o próprio Dewey, "é mais do que uma forma de governo; é, principalmente, uma forma de vida associada, de experiência conjunta e mutuamente comunicada" (DEWEY, 1959a, p. 93). Essa forma de vida associada e comunicada conduz a que os indivíduos sejam incentivados a variar seus atos, tenham uma diversidade maior de estímulos e consigam, assim, ampliar seu campo de interesse, passando a pautar suas próprias ações pelas ações dos outros e a considerar as ações alheias para orientar e dirigir as suas próprias. No entanto, adverte Dewey, "a ampliação da área dos interesses compartilhados e a libertação de maior diversidade de capacidades pessoais que caracterizam a democracia não são, naturalmente, resultado de deliberação e de esforço conscientes" (DEWEY, 1959a, p. 94). 
A efetivação da sociedade democrática foi resultado de um conjunto de fatores conjugados historicamente. O comércio, o desenvolvimento das indústrias, as migrações, as intercomunicações, os avanços científicos são alguns desses fatores que possibilitaram os germes da sociedade democrática. Contudo, sua existência não é garantia de sua permanência. Por isso, sua conservação e ampliação exigem esforço constante de todos os envolvidos, aspecto em que a educação se faz imprescindível. Em sociedades divididas em castas, a educação preocupa-se verticalmente com a formação da classe dirigente, ao passo que uma sociedade democrática, "cheia de canais distribuidores de todas as mudanças ocorridas em qualquer parte", ressalta Dewey, "deve tratar de fazer que seus membros sejam educados de modo a possuírem iniciativa individual e adaptabilidade" (DEWEY, 1959a, p. 94). É por isso que, para Dewey, a ciência, a filosofia e a educação devem servir de instrumentos na reconstrução permanente da democracia, tematização do nosso próximo tópico.

\section{A ciência, a filosofia e a educação como instrumentos na reconstrução da democracia}

No tópico anterior tratamos da concepção democrática de educação em Dewey. Vimos que para ele a educação é uma função social que assegura a direção e o desenvolvimento dos imaturos, por meio de sua participação na vida da comunidade a que pertencem. Nesse processo é de fundamental importância compreender que a educação variará de acordo com a qualidade da vida que predominar no grupo. Por isso, uma sociedade que almeja "mudança" e faz da "transformação" um ideal de vida necessita ter normas e métodos educativos diferentes daqueles de sociedades que não aspiram a semelhantes ideais. Mas quais são os instrumentos que possibilitam a efetivação das normas e métodos educativos para a atualização e reconstrução permanente da sociedade democrática?

Para Dewey, há um instrumento definitivamente humano, que é capaz de atuar no meio social e que necessita da vida comunal para encontrar seu verdadeiro e único babitat: trata-se da inteligência humana. Mas no que consiste a inteligência humana para Dewey? Por que ela necessita da vida comunal para encontrar seu verdadeiro habitat? De que maneira ela atua neste habitat? Que implicações tem para a concepção deweyana de educação? Para Dewey, "a inteligência é um bem, um ativo social, que ser reveste de função tão pública quanto é, concretamente, sua origem na cooperação social” (DEWEY, 1970, p. 69). O que nos diz essa definição?

Primeiramente, é necessário constatar que a inteligência só pode funcionar efetivamente como um recurso social, justamente porque sua gênese está circunscrita a uma atmosfera fortemente socializada. De outra parte, 
seu fortalecimento e seu desenvolvimento só se tornam possíveis dentro da organização social da qual a inteligência faz parte. "Tudo isso explica, perfeitamente", segundo a interpretação da pesquisadora Maria Nazaré Amaral, "a magnífica homogeneidade comunal que parece enriquecer o significado profundo da democracia como a única forma de vida digna do ser humano" (AMARAL, 1990, p. 77). Assim, a inteligência humana é o único instrumento que, graças às suas características estruturais, é capaz de captar com perfeição a fé na democracia, ou seja, a fé na capacidade inteligente de o homem comum responder, com senso comum, ao livre jogo dos fatos e das ideias. De outra parte, a vida comunal é o fundamental alicerce para que a inteligência humana consiga se desenvolver adequadamente e, assim, haja a atualização e reconstrução permanente da sociedade democrática.

Fé na capacidade inteligente do homem e fé na democracia são os dois pilares instituídos por Dewey para assegurar as condições da livre investigação e da livre comunicação. É esta composição que lhe possibilita substituir a "busca da certeza teórica pela busca da segurança prática” (AMARAL, 1990, p. 91). Que implicações tem essa substituição? De que maneira Dewey justifica a condicionalidade da validade de uma crença na efetivação do processo de investigação? Como ele compreende a investigação?

Primeiramente, é importante esclarecer que "pensamento reflexivo", "inteligência", "método da inteligência" e "investigação" são tomados por Dewey como termos sinônimos. Em seu livro "Como pensamos", ao descrever as funções essenciais da atividade reflexiva, Dewey (1959b, p. 111-112) define cinco fases ou aspectos do pensamento reflexivo: sugestões, intelectualização, hipótese, raciocínio e verificação. Percebe-se nessas cinco fases uma coincidência muito grande com os procedimentos do método científico. Assim, é possível dizer que, para Dewey, há uma profunda identidade entre o método da inteligência e o método científico, como se pode constatar na seguinte passagem de seu livro "Liberalismo, liberdade e cultura": "A humanidade está hoje na posse de um novo método, o da ciência experimental e cooperativa, o qual constitui o método da inteligência" (DEWEY, 1970, p. 83). O entusiasmo de Dewey pelos progressos da ciência e pelo uso do método da inteligência é reforçado em várias outras passagens com a intenção de nos lembrar que o apoio oferecido pelos métodos científicos é amplamente importante para a manutenção das instituições democráticas.

Para Dewey, há um profundo caráter social e público da ciência, pois seus enunciados não são tirados de abstrações infundadas; sua investigação não se dá na escuridão do anonimato; seu modo de proceder não está ancorado em opiniões subjetivas; seus resultados não são escondidos da grande maioria da sociedade. Ao contrário disso, o método científico caracteriza-se pela objetividade 
de seus enunciados, expõe publicamente sua investigação, o que possibilita a autocorreção, utiliza procedimentos (métodos) rigorosos e seus resultados são amplamente divulgados. Como nos diz a pesquisadora Maria Nazaré Amaral, "se a causa maior é a defesa de uma tradição democrática, os métodos a serem utilizados deverão também assentar-se sobre sólidas bases democráticas. É nesse sentido que fazemos questão de ressaltar o caráter verdadeiramente social que Dewey atribui à ciência" (AMARAL, 1990, p. 93).

Dewey está confiante de que o método científico, ou método da inteligência, não se restringe apenas à investigação dos fatos físicos (ciências naturais ou exatas), mas pode ser utilizado na solução de problemas sociais que tanto perturbam a sociedade atual, expressando a convicção de que é possível atualizar e superar os perversos dualismos entre conhecimento e crença, teoria e prática, ciência e moral. "Na medida em que meu estudo e meu pensamento progrediram", confessa o próprio Dewey em From absolutim to experimentalism, "inquietou-me mais e mais o escândalo intelectual que, para mim, estava implicado no corrente (e tradicional) dualismo de critério lógico e método, entre algo chamado 'ciência', de um lado, e algo chamado 'moral', de outro" (DEWEY, 1930 apud AMARAL, 1990, p. 95-96). Por isso, o método da inteligência ou científico poderia ser indicado como instrumento potente para superar o dualismo e restabelecer a ligação entre as crenças que os indivíduos possuem a respeito do mundo e as crenças sobre os valores que dirigem suas condutas. $\mathrm{O}$ universo da ciência e o reino dos valores, para Dewey, não precisam se excluir mutuamente, mas, sim, se complementar, como já ocorria entre os gregos.

Assim, a utilização do método da inteligência, visto como fator essencialmente social e constituído na concretude da ação, "consiste em converter a experiência passada em conhecimento e projetar esse conhecimento em idéias e propósitos que antecipam o que está por vir no futuro e indicam como realizar o desejado" (em citações desta data a palavra idéia tinha acento). (DEWEY, 1970, p. 55). A ideia de "converter a experiência passada em conhecimento" é recorrente na obra de Dewey e vem, mais uma vez, ressaltar a importância que os hábitos e crenças possuem no processo educacional como "reconstrução e reorganização da experiência". "Dependemos sempre da experiência acumulada no passado", diz Dewey (1970, p. 54), "mas, como estão sempre a surgir novas forças e a aparecer novas necessidades, temos de reconstruir os moldes da experiência velha para que as novas forças operem e as novas necessidades sejam atendidas". Numa sociedade dinâmica como é a sociedade democrática, tornase essencial que o método da inteligência seja capaz de "efetuar uma conexão funcional entre as novas condições e os velhos hábitos, costumes e instituições e crenças" (DEWEY, 1970, p. 56). Desse modo, é possível dizer, com certa segurança, que a ciência para Dewey deixa de ser uma simples arte de aceitar as 
coisas tal como as sentimos e gozamos e se transforma cada vez mais numa "arte de domínio" do homem sobre as coisas que o rodeiam.

E qual o papel da filosofia nesse processo de efetivação das normas e métodos educativos para a atualização e reconstrução permanente da sociedade democrática? Como se localiza a filosofia na utilização do método da inteligência? Que relação existe entre a filosofia e a ciência no processo de reconstrução permanente da democracia? Na introdução da obra "Reconstrução em filosofia", escrita em 1948', Dewey afirma que "uma filosofia, ajustada ao presente, deve ocupar-se com os problemas resultantes das mudanças que se processam com rapidez crescente, de dia para dia, numa área humano-geográfica, cada vez mais ampla e com rapidez de penetração mais profunda" (DEWEY, 1959c, p. 18). É nessa mesma introdução que ele esclarece a acepção do conceito de inteligência, o qual não pode ser compreendido como sinônimo de "razão", de "intelecto puro" ou de "faculdade" capaz de captar as últimas verdades. "Inteligência", diz Dewey, "é a designação sinóptica dos grandes métodos, em crescentes desenvolvimentos, de observação, de experimentação e de raciocínio reflexivo, que, não obstante haverem revolucionado em reduzido espaço de tempo, não só as condições físicas, como também em grau considerável, as condições fisiológicas da vida" (DEWEY, 1959c, p. 20). Dewey quer, portanto, que a reconstrução em filosofia seja capaz de adotar os procedimentos eficientes das ciências físicas, cabendo-lhe a missão de coordenar e integrar os resultados obtidos pela ciência. "A filosofia, nestas condições" - as palavras são do próprio Dewey - "não se sente em oposição à ciência. É antes um agente do enlace entre as conclusões da ciência e os modos de ação social e pessoal com os quais se projetam e se buscam possibilidades acessíveis” (DEWEY, 1960 apud AMARAL, 1990, p. 99).

A filosofia na perspectiva deweyana não pode ser um trono de contemplação da verdade isolada dos problemas reais da vida, mas deve refletir sobre as necessidades congruentes da vida atual, ou seja, "deve encarar tais necessidades sob o ângulo dos fins e valores democráticos que devem reger todas as fases de nossa vida" (AMARAL, 1990, p. 109). Assim, cabe à filosofia um papel de participação ativa nas lutas e nos debates da vida, em que o presente, o atual e o existencial são o problemático a ser enfrentado. Esse papel ativo da filosofia pode ser interpretado por muitos como um "estreitamento" da nobre condição que sempre ostentou essa instigante atividade intelectual milenar. Para Dewey, tal atitude não representa enfraquecimento da função importante que a filosofia

\footnotetext{
${ }^{1}$ Dewey havia escrito Reconstruşão em filosofia em 1920, logo após a Primeira Guerra Mundial. Nesta obra ele elabora um balanço das tendências do pensamento filosófico com o intuito de apresentar as concepções epistemológicas e educacionais que passaria a adotar. Em 1948, escreveu uma ampla introdução "na firme crença de que os acontecimentos dos anos intermediários criaram uma situação em que a necessidade da reconstrução dos princípios filosóficos é muito mais urgente do que o era quando o livro foi composto" (DEWEY, 1959c, p. 17).
} 
tem e terá na sociedade democrática; ao contrário, é sinal de otimismo e fortaleza. Acompanhemos as suas próprias palavras:

Eu tenho atribuído à filosofia uma função mais humilde do que aquela que, frequentemente, lhe assinalam. Mas modéstia, em última instância, não é incompatível com audácia na manutenção dessa função humilde como possa ser. Uma combinação de modéstia e coragem proporciona o único meio que conheço para que o filósofo possa olhar seu companheiro na face com franqueza e com humanidade (DEWEY, 1960 apud AMARAL, 1990, p. 114).

Que consequências todas essas reflexões deweyanas têm para a educação? Qual seu papel na configuração da reconstrução permanente da democracia? De que maneira a educação se articula com a ciência e com a filosofia? Para Dewey, a educação é o verdadeiro instrumento que possibilita mais crescimento e mais aperfeiçoamento em vista da construção de uma sociedade democrática. Por isso, educação é compreendida como vida, e vida é crescer, é desenvolver-se. Por essa definição podemos entender que "o objetivo da educação é habilitar os indivíduos a continuar sua educação - ou que o objeto ou recompensa da educação é a capacidade para um constante desenvolvimento" (DEWEY, 1959a, p. 108). Todavia, para que tal objetivo se concretize é necessário que haja cooperação mútua entre os homens e condições favoráveis para sua efetivação (instituições sociais adequadas), ou seja, a existência de uma sociedade democrática.

$\mathrm{Na}$ perspectiva deweyana, a educação tem a grande tarefa de possibilitar a realização máxima do crescimento do ser humano. Não se trata de um crescimento puramente biológico, mas de um crescimento intelectual, somente possível pelo exercício de uma vida reflexiva, que se efetiva na medida em que ocorre o desenvolvimento do pensamento reflexivo. Mas no que consiste o pensamento reflexivo? De que maneira Dewey caracteriza seu desenvolvimento? Em seu texto "Como pensamos", mencionado anteriormente, em uma de suas partes, propõe-se a analisar o "processo e o produto do pensamento". É nesta parte da obra que descreve a famosa ideia de que "aprender é aprender a pensar"2 constitui uma das principais tarefas da educação. "Pessoas que pensam", afirma Dewey, "são cautelosas, não precipitadas; olham em torno, são circunspectas, não andam às cegas" (DEWEY, 1959b, p. 84).

Para ele, enganam-se todos aqueles que confinam o processo educativo a um simples faz̧er espontâneo, pois uma autêntica educação abrange não só “a

\footnotetext{
${ }^{2}$ As publicações recentes sobre educação enfatizam a ideia do "aprender a aprender" como sendo uma novidade. Em seu livro "Sociedade do conhecimento ou sociedade das ilusões?", o professor e pesquisador educacional Newton Duarte, 2003 faz uma crítica às pedagogias das competências mostrando que são devedoras da corrente educacional contemporânea, a qual ele chama de pedagogias do "aprender a aprender". Philippe Perrenoud é um dos autores criticados por Duarte no sentido de mostrar que aquilo que muitas vezes é apresentado como novidade não passa de uma reformulação de ideias que já foram desenvolvidas em tempos passados.
} 
formação de atitudes práticas de eficiência, o robustecimento e desenvolvimento de disposições morais, o cultivo de apreciações estéticas" (DEWEY, 1959b, p. 85), mas, também, um elemento de significado consciente (aspecto intelectual). "Sem este", conclui Dewey, "a atividade prática torna-se mecânica e rotineira, a moral, cega e arbitrária, a apreciação estética, um sentimento derramado" (DEWEY, 1959b, p. 85-86). Portanto, o pensamento reflexivo no processo educacional constitui um pensar cuidadoso, sistemático, enfim, um pensar com arte.

\section{Considerações finais}

Pelo exposto, percebemos que uma das incansáveis lutas que perpassa toda a obra de Dewey foi a de reconstruir permanentemente a sociedade democrática. Sua profunda fé na democracia transformou-se em credo pedagógico à luz do qual foi capaz de sistematizar os principais elementos para forjar uma proposta de educação em que a filosofia e a ciência se tornariam instrumentos fundamentais para a efetivação da sociedade democrática. A filosofia para Dewey deixa de ser uma atividade abstrata, uma especulação estéril, com pretensão de alcançar a realidade suprema e absoluta, e passa a exercer a função civilizadora, de esclarecer as forças morais que regem a humanidade no sentido de contribuir para que os homens atinjam suas aspirações, conquistando uma felicidade mais organizada e inteligente. "Dizer que a filosofia possui uma função civilizadora significa atribuir-lhe responsabilidade diante das intensas e incertas mudanças que atingem a existência humana" (CUNHA, 1994, p. 34). Assim, a filosofia tem a tarefa de auxiliar na busca de novos modos de ação diante dos acontecimentos que afetam uma forma estabelecida de vida. Esta função civilizadora da filosofia está numa apropriada sintonia com a ideia de sociedade democrática deweyana, ou seja, uma sociedade que necessita absorver as mudanças que se processam de forma contínua e que continuamente precisa rever suas formas padronizadas de vida.

A democracia, para Dewey, constitui a possibilidade da superação da tradicional dicotomia entre indivíduo e sociedade; ou seja, a dimensão individual é, ao mesmo tempo, coletiva, pois a democracia só existe quando a plena satisfação do indivíduo se realiza na cooperação entre todos os envolvidos.

Observações da correção:

1. Note-se que muitas vezes foi substituída (às vezes, simplesmente retirada) a expressão usada reiteradas vezes "nosso filósofo da educação". Isso foi feito para dar uma sustentação mais adequada ao uso de termos em um artigo científico. 


\section{Referências}

AMARAL, M. N. de C. P. Dewey: filosofia e experiência democrática. São Paulo: Perspectiva, 1990.

CUNHA, M. V. da. John Dewey: uma filosofia para educadores em sala de aula. Petrópolis: Vozes, 1994.

DEWEY, J. Democracia e educação: introdução à filosofia da educação. Trad. Godofredo Rangel e Anísio Teixeira. 3. ed. São Paulo: Companhia Editora Nacional, 1959a.

Como pensamos. Trad. Hayée de Camargo Campos. 3 ed. São Paulo: Companhia Editora Nacional, 1959b.

. Reconstrução em filosofia. Trad. António Pinto de Carvalho. 2 ed. São Paulo: Companhia Editora Nacional, 1959c.

Liberalismo, liberdade e cultura. Tradução de Anísio Teixeira. São Paulo: Companhia Editora Nacional, 1970.

DUARTE, N. Sociedade do conhecimento ou sociedade das ilusões? Campinas: Autores Associados, 2003.

JAEGER, W. Paidéia: a formação do homem grego. Tradução de Arthur M. Pereira. 2. ed. São Paulo: Martins Fontes, 1989.

KILPATRIC, W. Educação para uma civilização em mudança. Tradução de Noemi Rydilfer. 16. ed. São Paulo: Melhoramentos, 1978.

LAMOUNIER, B. Tocqueville - vida e obra. In: TOCQUEVILLE, A. A democracia na América. Tradução de J. A. G. Albuquerque. São Paulo: Abril Cultural, 1985.

TOCQUEVILLE, A. A democracia na América. Tradução de J. A. G. Albuquerque. São Paulo: Abril Cultural, 1985.

VERNANT, J-P. As origens do pensamento grego. Tradução de Ísis Borges B. da Fonseca. 9. ed. Rio de Janeiro: Bertrand Brasil, 1996.

Recebido em 17/07/2011

Versão final recebida em 14/08/2011

Aceito em 03/09/2011 